\title{
'More eyes on the problem': What the social sciences and humanities allow us to see and do in response to COVID-19
}

The COVID-19 pandemic has bared the fragile and unequal social and economic structures underlying South Africa, and in this issue of the Journal we foreground what contributions the humanities and social sciences can make to charting a path into an improved future.

We are fortunate that Jonathan Jansen, President of the Academy of Science of South Africa, gathered a group of multidisciplinary essays each written by an expert. Jansen, Distinguished Professor in the Faculty of Education at Stellenbosch University, is a leading intellectual, fearless author, and acclaimed researcher. At his invitation, we present a diverse series of Invited Commentaries that will have lasting value for our country in the difficult period that lies ahead. There are challenges but opportunities too.

When the world's most well-known infectious diseases expert was interviewed about the alarming rate of COVID-19 infections in his country (the USA), Anthony Fauci appealed for caution 'until we have more eyes on the problem'. It is an apt metaphor for what this collection of Invited Commentaries seeks to do - to provide 'more eyes' on the pandemic by drawing in perspectives from the social sciences and the humanities. Until now, the views of scientists such as epidemiologists, virologists and immunologists have enjoyed prominence in advising government on its responses to the pandemic.

The dominance of medical scientists in the initial response to the pandemic is of course understandable given the imminence of the viral threat to human health and human lives. But the limits of medical science evidence alone soon became evident.

Social distancing as a mitigating factor did not take account of crowded human settlements. Restriction of the number of mourners at funerals was made without attending to rituals of mourning and meaning-making in communities. Return of children to schools was gazetted without insights into how schools function as organisations and what that implies for re-opening under strict conditions. Enforcing of lockdown regulations was often done with little regard for the values of the Constitution and the rights of citizens. These were clearly not issues that could be resolved using epidemiological data alone.
Unsurprisingly, the wheels of scientific decorum came off within the science community even as debates raged in the broader public about the easing of lockdown restrictions.

We asked some of the leading social science and humanities scholars in South Africa to throw new eyes on the problem of COVID-19 from the vantage point of their particular disciplines by answering two questions:

1. What does your discipline allow us to better understand with respect to the social and human(e) aspects of COVID-19?

2. What do the insights from your discipline allow us to do differently in the context of the pandemic?

We bring together perspectives from only 11 fields or disciplines given limitations of time and space; these are economics, anthropology, law, political science, ethics, education, history, sociology, religion studies, language and philosophy.

Here - for the first time - is a collection of the best ideas for understanding the social nature of the COVID-19 pandemic and its consequences for humanity. The contributions are at once intellectual and practical as they speak to the many other facets of COVID-19 which we now know is as much a scientific puzzle as it is a social problem in these uncertain times.

\section{HOW TO CITE:}

Jansen J. 'More eyes on the problem': What the social sciences and humanities allow us to see and do in response to COVID-19. S Afr J Sci. 2020;116(7/8), Art. \#8501, 1 page. https:// doi.org/10.17159/sajs.2020/8501 